\title{
Híbridos pré-comerciais resistentes a Tuta absoluta obtidos de linhagem de tomateiro rica em acilaçúcares
}

\author{
Gabriel M Maciel; Wilson Roberto Maluf; Vanisse de Fátima Silva; Álvaro Carlos Gonçalves Neto; Luiz \\ Antônio Augusto Gomes
}

UFLA-DAG, C. Postal 3037,37200-000 Lavras-MG; gmmufla@gmail.com; wrmaluf@dag.ufla.br; vanissesilva@yahoo.com; alvarocgneto@gmail.com; laagomes@dag.ufla.br

\begin{abstract}
RESUMO
O trabalho foi realizado com o objetivo de avaliar o potencial agronômico de híbridos de tomateiro a partir da linhagem TOM687, rica em acilaçúcares e de resistência comprovada a pragas. $\mathrm{O}$ experimento foi instalado na HortiAgro, município de Ijaci, MG. Foi constituído de 30 genótipos ( 5 híbridos comerciais, 1 linhagem pré-comercial (TOM-687), e 24 híbridos nos quais TOM-687 foi utilizada como um dos pais), os quais foram conduzidos em tutoramento com haste dupla, no espaçamento de $1,30 \times 0,50 \mathrm{~m}$, totalizando 15.385 plantas por hectare. Foram realizadas nove colheitas, entre as datas de 01/11/08 a 28/11/08. Foram avaliadas as características de massa média por fruto $\left(\mathrm{g}_{\text {fruto }}{ }^{-1}\right)$ e produção por hectare $\left(\mathrm{t} \mathrm{ha} \mathrm{a}^{-1}\right)$. Os 24 híbridos que tiveram TOM-687 como um dos pais apresentaram potencial produtivo similar ao das testemunhas comerciais Débora Max, Bravo, Bônus, Kombat e Atyna. Dos 24 híbridos experimentais, quatro (TEX-298, TEX-310, TEX-315 e TEX-316) foram avaliados quanto à resistência à traça-do-tomateiro (Tuta absoluta) e mostraram-se mais resistentes do que as testemunhas comerciais.
\end{abstract}

Palavras-chave: Solanum pennellii, vigor híbrido, acilaçúcar.

\begin{abstract}
Pre-commercial hybrids obtained from an acylsugar-rich tomato inbred line, resistant to Tuta absoluta

This experiment was designed to assess the agronomic potential of tomato hybrids obtained from the tomato line TOM-687, an acylsugar-rich line with confirmed resistance to an array of tomato pests. The experiment was carried out at the HortiAgro Sementes research station, in Ijaci, Minas Gerais State, Brazil. The treatments comprised 30 genotypes ( 5 commercial hybrid checks, 1 high acylsugar line (TOM-687), and 24 hybrids in which TOM-687 was one of the parents). Plants were trained to two stems, in a spacing of $1.30 \mathrm{~m}$ between rows $\mathrm{x} 0.50 \mathrm{~m}$ between plants within a row, totaling 15,385 plants per hectare. Nine harvests were performed between November $1^{\text {st }}, 2008$ and November $28^{\text {th }}, 2008$. Traits assessed were mean fruit weight $\left(\mathrm{g}_{\text {fruit }}{ }^{-1}\right)$ and total yield $\left(\mathrm{t} \mathrm{ha}^{-1}\right)$. All 24 hybrids with TOM-687 as a parent showed yields similar to those of the commercial check hybrids Débora Max, Bravo, Bônus, Kombat and Atyna. Four of these experimental hybrids (TEX-298, TEX310, TEX-315 and TEX-316) were assessed for resistance to the South American tomato pinworm Tuta absoluta, and were shown to possess higher degrees of pest resistance than the current commercial hybrid checks.
\end{abstract}

Keyword: Solanum pennellii, hybrid vigor, acylsugar.

(Recebido para publicação em 23 de fevereiro de 2010; aceito em 14 de abril de 2011)

(Received on February 23, 2010; accepted on April 14, 2011)

\begin{abstract}
$\mathrm{A}^{\mathrm{n}}$ pesar de ser uma das mais importantes hortaliças cultivadas, o tomateiro possui vários problemas fitossanitários (Suinaga et al., 2003). A traça-do-tomateiro (Tuta absoluta) é atualmente uma das pragas mais importantes do tomateiro cultivado no Brasil. O controle dessa praga pelos tomaticultores é feito predominantemente via aplicação de inseticidas químicos (Benvenga et al., 2007). Espécies selvagens de tomateiro, particularmente a espécie Solanum pennellii (sin. Lycopersicon pennellii), têm sido amplamente utilizadas como fonte de resistência a pragas no melhoramento genético. Acessos de $S$. pennellii possuem altos níveis de resistência a grande número de artrópo-
\end{abstract}

des-praga, e esta resistência é mediada por acilaçúcares (AA) presentes nos folíolos (Resende et al., 2006; Maciel, 2008; Pereira et al., 2008; Resende et al., 2008;). Gonçalves et al. (2007) indicaram que altos teores de acilaçúcares se devem à ação de um alelo recessivo, com dominância incompleta no sentido de baixos teores. Em virtude da dominância incompleta do alelo que controla resistência, foi possível a obtenção de híbridos resistentes a artrópodes-praga, mesmo cruzando-se linhagens com alto teor de AA com linhagens com baixo teor. Maciel (2008) testando diferentes combinações híbridas entre linhagens com altos teores e linhagens com baixos teores de AA, comprovou serem elas resistentes à mosca-branca, à traça-do-tomateiro e ao ácaro-rajado (Tetranychus urticae), demonstrando que a utilização de apenas um genitor com alto teor de AA é suficiente para obter híbridos resistentes a um amplo espectro de pragas da cultura.

Embora a resistência a pragas em tomateiro mediada por AA derivados de $S$. pennellii seja bem documentada (Liedl et al., 1995; Resende et al., 2006; Saeidi et al., 2007; Maciel, 2008; Resende et al., 2008), ainda não estão disponíveis no mercado tomateiros comerciais com níveis satisfatórios de resistência. Com intuito de selecionar quais, entre três linhagens com alto teor de AA disponíveis (TOM-687, TOM-688 e TOM-689), 
apresentavam maior potencial para uso como genitores de híbridos comerciais, Maciel et al. (2009) avaliaram suas capacidades combinatórias em cruzamento dialélico. No referido estudo, ficou comprovada a superioridade das linhagens TOM-687 e TOM-688 quanto à capacidade combinatória para características de interesse agronômico (produtividade e massa média de frutos). Desta forma, TOM-687 mostrou-se altamente promissora para o desenvolvimento de novos híbridos comerciais de tomateiro com amplo espectro de resistência a pragas da cultura.

O objetivo do trabalho foi avaliar o potencial agronômico de novos híbridos de tomateiro obtidos a partir da linhagem melhorada TOM-687, e confirmar sua efetividade no controle da traça-do-tomateiro através de resistência genética.

\section{MATERIAL E MÉTODOS}

O experimento no campo foi realizado de 07/08 a 11/08, na Estação Experimental de Hortaliças da HortiAgro Sementes Ltda, Fazenda Palmital,

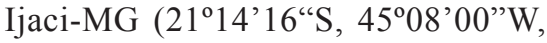
altitude média de $918 \mathrm{~m}$ ).

A linhagem melhorada TOM-687, rica em AA, foi obtida a partir do cruzamento interespecífico inicial entre Solanum lycopersicum (= Lycopersicon esculentum) TOM-584 (linhagem pré-comercial de tomateiro, com boas características agronômicas, e baixo teor de AA) x Solanum pennellii LA-716 (acesso com alto teor de AA nos folíolos). Plantas com altos teores de AA da geração $\mathrm{F}_{2}$ deste cruzamento interespecífico foram selecionadas por Resende et al. (2006) e tiveram comprovada sua resistência à traça-do-tomateiro à mosca-branca e ao ácaro-rajado (Resende et al., 2008). Seguiram-se três gerações de retrocruzamentos e autofecundações para o genitor recorrente TOM-584, tendo sido efetuadas a cada ciclo de retrocruzamento/autofecundação seleções para altos teores de acilaçúcares (Pereira et al., 2008; Gonçalves Neto, 2008).

Após sucessivas autofecundações foram obtidas três linhagens com alto teor de AA, entre as quais as linhagens
TOM-687 e TOM-688 apresentaram melhor capacidade combinatória (Maciel et al., 2009). A linhagem TOM-687 possui hábito de crescimento indeterminado, frutos bi e triloculares, com formato tipo Santa Cruz, e alto teor de acilaçúcares, e compara-se, em termos agronômicos, a cultivares comerciais de tomateiro do grupo Santa Cruz atualmente comercializadas no mercado brasileiro (Débora Max, Bravo, Bônus, Santa Clara). Por suas características agronômicas aliadas a seu alto teor de acilaçúcares, TOM-687 foi considerada promissora para a obtenção de híbridos resistentes a pragas (Maciel, 2008).

Foram obtidos 24 híbridos experimentais utilizando-se a linhagem TOM687 como doadora de pólen (genitor masculino). Como genitores femininos foram utilizadas 24 linhagens pré-comerciais com baixos teores de AA, porém portadoras de genes que conferem resistência a doenças: $V=$ murcha de verticílio (Verticillium dahliae); $F(1)=$ murcha de fusário raças 1 (Fusarium oxysporum f.sp. lycopersici); $F(2)=$ murcha de fusário raça 2 (Fusarium oxysporum f.sp. lycopersici); $S m=$ mancha do Stemphylium; Sw-5= tospovírus (fonte de resistência: cv. Stevens), $S w$ $-R T=$ tospovírus (fonte de resistência: cv. Rey de Los Tempranos); Pto= Mancha bacteriana (Pseudomonas syringae pv. tomato); $M i=$ nematóide (Meloidogyne incognita,M.javanica) e, Ty-1=Begomovirus, de modo que os híbridos experimentais obtidos (TEX-283 e TEX-295 a TEX-317) possuem uma gama de resistências presumidas a pragas e doenças. Os teores de acilaçúcares nos folíolos não foram determinados no presente ensaio, mas são presumivelmente intermediários entre os do genitor com alto teor de AA (TOM-687) e o do respectivo genitor com baixo teor de AA conforme resultados de pesquisa obtidos por Maciel (2008) níveis suficientes, para conferir-lhes bons níveis de resistência à traça-do-tomateiro, à mosca-branca e ao ácaro-rajado.

Os 24 híbridos foram avaliados juntamente com os híbridos comerciais Débora Max (Sakata), Bravo (Agristar), Bônus (Agristar), Kombat (Hortec), Atyna (HortiAgro/Hortec), bem como com a linhagem parental TOM-687.
Sementes dos 30 genótipos a serem testados foram plantadas em 15/07/08 em bandejas de poliestireno de 128 células, utilizando como substrato o produto comercial Plantmax ${ }^{\circledR}$. As plântulas foram transplantadas para o campo no estádio de quatro a seis folhas definitivas em 14/08/08, sendo tutoradas com duas hastes em linhas duplas, no espaçamento de $1,30 \times 0,50 \mathrm{~m}$, totalizando 15.385 plantas por hectare. Cada parcela foi constituída por 20 plantas. Utilizou-se uma bordadura delimitando toda área experimental do campo.

Realizou-se a condução do experimento de acordo com as recomendações de cultivo comercial de tomate em nível de campo (Alvarenga, 2004), realizando irrigações (gotejamento), pulverizações, capinas, desbrotas e amarrios em função da necessidade. As adubações de plantio foram feitas com o adubo formulado 08-28-16, Super Simples, Yoorin e composto orgânico Gene Plus nas respectivas dosagens de 100,60, 50 e $400 \mathrm{~g}$ por metro linear de canteiro. As adubações complementares de cobertura foram feitas por fertirrigação. As colheitas foram realizadas de 01/11/08 a 28/11/08 totalizando nove colheitas. Foram avaliados a massa média de fruto $\left(\mathrm{g}\right.$ fruto $\left.^{-1}\right)$ e produção por hectare $\left(\mathrm{t} \mathrm{ha}^{-1}\right)$. Foi utilizado o delineamento em blocos casualizados com três repetições e as médias de tratamentos comparadas pelo teste de Tukey a 5\% de probabilidade.

Para a realização do teste de resistência à $T$. absoluta foram testados quatro híbridos (TEX-298, TEX-310, TEX-315 e TEX-316), todos eles com teores presumivelmente intermediários de AA em virtude de possuírem o genitor comum TOM-687. Foram também testadas as quatro respectivas linhagens utilizadas como parentais femininos (TOM-650, TOM-694, TOM-699 e TOM-700, todas com baixo teor de AA), a linhagem genitora comum TOM-687 (alto teor de AA), o acesso selvagem LA-716 ( $S$. pennellii, testemunha com alto teor de AA), dois híbridos comerciais (Bravo e Bônus, testemunhas com baixo teor de AA) e a cultivar não híbrida Santa Clara (testemunha com baixo teor de AA).

Para a infestação com a traça-do-tomateiro, foi previamente estabelecida uma criação do inseto, em estufa 
constituída por estrutura de proteção de $12 \mathrm{~m}^{2}$ (4 x $3 \mathrm{~m}$ ), modelo capela, com cobertura de plástico transparente de 100 micras de espessura e laterais de tela antiafídica. Foram coletadas, em lavoura de tomate, pupas presentes nas folhas de tomateiro e adultos no último ínstar, os quais foram transferidos para estufa telada localizada no Setor de Olericultura e Experimentação da UFLA, em Lavras-MG.

Em 07/04/09 foi realizada a semeadura dos 13 tratamentos em bandejas de poliestireno com 128 células utilizando substrato Plantmax ${ }^{\circledR}$. Em 05/05/09 foi realizado o transplante das mudas para vasos de 3,44 L de substrato. Decorridos trinta dias após o transplante, todos os genótipos/tratamentos foram colocados em estufa telada, previamente infestada, com uma população de traça-do-tomateiro mantida sob plantas da cultivar Santa Clara.

$\mathrm{O}$ delineamento experimental foi inteiramente casualizado, com uma planta (vaso) por parcela e seis repetições por tratamento, totalizando 78 vasos na estufa. Aos vinte e quatro dias após o início da infestação, foram realizadas avaliações da oviposição, através da contagem do número de ovos em $2 \mathrm{~cm}^{2}$ de área foliar com o auxílio de um microscópico estereoscópico binocular com aumento de 20 a 80 vezes. Foram feitas contagens nas duas faces (adaxial e abaxial) dos folíolos (30 folíolos) localizados no terço superior da planta. A média da parcela correspondeu ao número médio de ovos por $2 \mathrm{~cm}^{2}$ de folíolo.

Foram avaliados a partir dos 36 dias após a infestação os níveis de danos às plantas, através de escalas de notas variando de 1 (menor dano) a 5 (maior dano), propostas por Maluf et al. (1997) e Labory et al. (1999) para as seguintes características: lesões no folíolo (LF), porcentagem de folíolos atacados (PFA) e danos gerais à planta (DP).

Foram feitas dez avaliações de níveis de danos, uma a cada dois dias. A temperatura média e a umidade relativa do ar entre o período de infestação das plantas até o último dia de avaliação dos danos variaram de 18,5 a $27,4^{\circ} \mathrm{C}$ e 64,5 a $100 \%$ respectivamente. As médias das notas foram submetidas ao cálculo da área sob a curva de progresso dos danos ao longo do tempo, utilizando as notas atribuídas nas dez avaliações. Os valores obtidos foram transformados por $\sqrt{\mathrm{x}+0,5}$ antes de se efetuar a análise de variância, sendo no entanto tabulados (Tabela 3 ) os valores das médias não transformadas.

Os valores obtidos do cálculo das áreas sob as curvas e o número total de ovos foram submetidas à análise de variância por meio do aplicativo estatístico Sisvar (Ferreira, 2000), e as médias de tratamentos foram comparadas através do teste de Tukey a $5 \%$ de probabilidade. Foram obtidas ainda estimativas de

Tabela 1. Comparação das médias referentes ao ensaio agronômico de genótipos de tomateiro (comparison of averages on the test potential of genotypes of tomato). Lavras, UFLA, 2008.

\begin{tabular}{|c|c|c|}
\hline Genótipos $^{1}$ & $\begin{array}{c}\text { Massa média por fruto } \\
\text { (g/fruto) }\end{array}$ & $\begin{array}{c}\text { Produtividade total } \\
\text { (t/ha) }\end{array}$ \\
\hline Débora Max & 129,0 abcde & $58,0 \mathrm{ab}$ \\
\hline Bravo & 133,0 abcde & $59,0 \mathrm{ab}$ \\
\hline Bônus & 125,3 abcde & $60,0 \mathrm{ab}$ \\
\hline Kombat & 133,7 abcd & $62,0 \mathrm{a}$ \\
\hline Atyna & 122,0 abcde & $51,3 \mathrm{ab}$ \\
\hline TOM-687 & 126,7 abcde & $37,0 \mathrm{~b}$ \\
\hline TEX-295 & 127,0 abcde & $55,2 \mathrm{ab}$ \\
\hline TEX-296 & 127,7 abcde & $56,2 \mathrm{ab}$ \\
\hline TEX-297 & 124,0 abcde & $53,1 \mathrm{ab}$ \\
\hline TEX-298 & 118,0 abcde & $56,6 \mathrm{ab}$ \\
\hline TEX-299 & 127,0 abcde & $42,1 \mathrm{ab}$ \\
\hline TEX-300 & $113,3 \mathrm{de}$ & $44,1 \mathrm{ab}$ \\
\hline TEX-301 & $112,7 \mathrm{e}$ & $47,0 \mathrm{ab}$ \\
\hline TEX-302 & 124,3 abcde & $50,9 \mathrm{ab}$ \\
\hline TEX-303 & $136,3 \mathrm{abc}$ & $54,9 \mathrm{ab}$ \\
\hline TEX-304 & $127,3 \mathrm{abcd}$ & $43,4 \mathrm{ab}$ \\
\hline TEX-305 & 129,3 abcde & $46,4 \mathrm{ab}$ \\
\hline TEX-306 & 121,3 abcde & $43,4 \mathrm{ab}$ \\
\hline TEX-283 & $138,3 \mathrm{ab}$ & $50,9 \mathrm{ab}$ \\
\hline TEX-307 & 121,3 abcde & $49,9 \mathrm{ab}$ \\
\hline TEX-308 & 125,0 abcde & $51,5 \mathrm{ab}$ \\
\hline TEX-309 & 123,0 abcde & $44,1 \mathrm{ab}$ \\
\hline TEX-310 & 123,3 abcde & $48,5 \mathrm{ab}$ \\
\hline TEX-311 & 123,7 abcde & $47,8 \mathrm{ab}$ \\
\hline TEX-312 & 125,3 abcde & $53,4 \mathrm{ab}$ \\
\hline TEX-313 & 117,3 cde & $52,1 \mathrm{ab}$ \\
\hline TEX-314 & 126,0 abcde & $47,1 \mathrm{ab}$ \\
\hline TEX-315 & $134,0 \mathrm{abcd}$ & $56,5 \mathrm{ab}$ \\
\hline TEX-316 & $140,7 \mathrm{a}$ & $49,4 \mathrm{ab}$ \\
\hline TEX-317 & $138,7 \mathrm{ab}$ & $41,5 \mathrm{ab}$ \\
\hline Média Geral & 126,48 & 50,43 \\
\hline CV (\%) & 5,11 & 14,20 \\
\hline
\end{tabular}

${ }^{1}$ Médias seguidas da mesma letra nas colunas não diferem entre si pelo teste de Tukey ao nível de $5 \%$ de probabilidade $(\mathrm{p}=0.05)$ ( ${ }^{1}$ means followed by the same letter within the columns do not differ from each other by Tukey multiple range test $(\mathrm{p}=0.05))$. 
Tabela 2. Contagem de ovos (número de ovos por $2 \mathrm{~cm}^{2}$ de área foliar) e contrastes de interesse amostrados no terço superior das plantas de tomate aos 24 dias após infestação com Tuta absoluta (egg counts (number of eggs per $2 \mathrm{~cm}^{2}$ leaflet area) and contrast of interest measured on the upper third portion of the tomato plants 24 days after infestation with Tuta absoluta). Lavras, UFLA, 2008.

\begin{tabular}{llc}
\hline Genótipos & $\begin{array}{c}\text { Contagem de ovos } \\
\text { 1 } \\
\left(\mathbf{n}^{\mathbf{0}} \mathbf{\text { ovos}} \mathbf{2} \mathbf{~ c m}^{\mathbf{2}} \mathbf{\text { de área foliar } )}\right.\end{array}$ \\
\hline T1 & LA-716 & $1,16 \mathrm{~d}$ \\
T2 & TOM-687 & $8,50 \mathrm{c}$ \\
T3 & TEX-298 & $8,83 \mathrm{c}$ \\
T4 & TEX-310 & $7,83 \mathrm{c}$ \\
T5 & TEX-315 & $9,50 \mathrm{c}$ \\
T6 & TEX-316 & $10,50 \mathrm{bc}$ \\
T7 & TOM-650 & $16,16 \mathrm{a}$ \\
T8 & TOM-694 & $16,17 \mathrm{a}$ \\
T9 & TOM-699 & $16,10 \mathrm{a}$ \\
T10 & TOM-700 & $15,66 \mathrm{ab}$ \\
T11 & Bravo & $15,83 \mathrm{ab}$ \\
T12 & Bônus & $17,16 \mathrm{a}$ \\
T13 & Santa Clara & $20,16 \mathrm{a}$ \\
\hline
\end{tabular}

\section{Contrastes de interesse}

Estimativas dos contrastes

\begin{tabular}{ll}
\hline $\mathrm{C} 1$ & {$[(\mathrm{~T} 11+\mathrm{T} 12+\mathrm{T} 13) / 3-\mathrm{T} 1]$} \\
$\mathrm{C} 2$ & {$[(\mathrm{~T} 11+\mathrm{T} 12+\mathrm{T} 13) / 3-\mathrm{T} 2]$} \\
$\mathrm{C} 3$ & $[(\mathrm{~T} 11+\mathrm{T} 12+\mathrm{T} 13) / 3-(\mathrm{T} 3+\mathrm{T} 4+\mathrm{T} 5+\mathrm{T} 6) / 4)]$ \\
$\mathrm{C} 4$ & $[(\mathrm{~T} 3+\mathrm{T} 4+\mathrm{T} 5+\mathrm{T} 6) / 4)-\mathrm{T} 1]$ \\
$\mathrm{C} 5$ & $[(\mathrm{~T} 3+\mathrm{T} 4+\mathrm{T} 5+\mathrm{T} 6) / 4)-\mathrm{T} 2]$ \\
$\mathrm{C} 6$ & {$[(\mathrm{~T} 7+\mathrm{T} 8+\mathrm{T} 9+\mathrm{T} 10) / 4-(\mathrm{T} 3+\mathrm{T} 4+\mathrm{T} 5+\mathrm{T} 6) / 4)$}
\end{tabular}
( ${ }^{0}$ ovos $/ 2 \mathbf{~ c m}^{2}$ de área foliar)

${ }^{1}$ médias seguidas da mesma letra nas colunas não diferem entre si pelo teste de Tukey ao nível de $5 \%$ de probabilidade $(\mathrm{p}=0.05)$ ( ${ }^{1}$ means followed by the same letter within the columns do not differ from each other by Tukey multiple range test $(\mathrm{p}=0.05)) ; * *$ significativo a $1 \%$, *significativo a $5 \%$ e ns= não significativo pelo teste de Scheffé $(* *$ significant at $1 \%$, *significant at $5 \%$ and $n s=$ not significant, respectively, for the Scheffé test).

ram significativamente das testemunhas comerciais Débora Max, Bravo, Bônus, Kombat e Atyna (Tabela 1). Mereceram destaque os híbridos TEX-316, TEX283 e TEX-317 que apresentaram respectivamente massa média de frutos de 140,$7 ; 138,3$ e $138,7 \mathrm{~g} \mathrm{fruto}^{-1}$. A maioria dos híbridos experimentais apresentou excelente padrão de tamanho de frutos indicando potencial agronômico neste quesito. É importante ressaltar o valor da massa média de frutos de $126,7 \mathrm{~g}$ fruto $^{-1}$ obtido pela linhagem TOM-687, que não diferiu significativamente dos valores médios das testemunhas comerciais. Este fato corrobora os resultados encontrados por Maciel et al. (2009) que ressaltaram o padrão comercial de fruto da linhagem TOM-687.

Com relação à produtividade, todos os híbridos experimentais não se diferenciaram significativamente das testemunhas Débora Max, Bravo, Bônus e Atyna. A linhagem TOM-687, embora também não diferindo significativamente dos híbridos experimentais, apresentou níveis de produtividade numericamente inferiores a estes. Esta tendência de TOM-687 para menores níveis de produtividade não se fez sentir, no entanto, nos híbridos dos quais é genitor, uma vez que a grande maioria deles apresentou níveis de produtividade próximos aos de pelo menos uma das testemunhas comerciais. Portanto, os híbridos experimentais foram conside- rados, de maneira geral, potencialmente comercializáveis, tanto quanto as testemunhas.

Os resultados obtidos por Maciel (2008) demonstraram que híbridos com apenas um genitor rico em AA possuem teores intermediários de $\mathrm{AA}$ e níveis satisfatórios de resistência a $T$. urticae, $T$. absoluta e B. argentifolii. Neste sentido, a linhagem TOM-687 demonstrou ser possivelmente promissora, pois além de possuir alto teor de AA, e portanto, transmitir a seus híbridos uma gama de resistências a pragas, possui ótimo padrão agronômico, que se estende aos híbridos que a utilizam como linhagem parental.

As oviposições da traça-do-tomateiro foram em geral menores nos híbridos experimentais e na linhagem TOM-687 do que nas linhagens com baixo teor de AA (TOM-650, TOM-694, TOM-699 e TOM-700) ou nas testemunhas comerciais (Bravo, Bônus e Santa Clara) (Tabela 2). Significância (contraste C6, Tabela 2) foi observada ao se comparar os parentais femininos (genitoras dos híbridos experimentais) que apresentam baixo teor de AA (TOM-650, TOM-694, TOM-699 e TOM-700) com os híbridos experimentais (TEX-298, TEX-310, TEX-315 e TEX-316), indicando menores oviposições nos híbridos do que nas suas linhagens genitoras femininas. Embora não tão resistentes quanto o acesso 'LA-716 (contraste C4, Tabela 2), os híbridos (TEX-298, TEX-310, TEX-315 e TEX-316) apresentaram níveis satisfatórios de resistência a $T$. absoluta. Fica evidente que altos teores (TOM-687) ou intermediários (TEX298, TEX-310, TEX-315 e TEX-316) de AA nos folíolos levaram a uma menor oviposição da traça-do-tomateiro relativamente aos genótipos com baixo teor de AA, sejam eles as testemunhas comerciais (contrastes C2, C3, Tabela 2) ou linhagens parentais (contraste C6, Tabela 2). Não houve diferenças significativas para oviposição entre os híbridos e sua linhagem genitora TOM-687 (contraste C5, Tabela 2), indicando que níveis intermediários de AA nos híbridos foram tão eficientes quanto o alto nível de AA da linhagem para esta característica. Ficou implícito um mecanismo de resistência do tipo 
Tabela 3. Valores obtidos das áreas sob as curvas de progresso dos danos ao longo do tempo para danos na planta (DP); lesão nos folíolos (LF); porcentagem de folíolos atacados (PFA); e estimativas dos contrastes de interesse entre genótipos de tomateiro, amostrados entre 36-54 dias após infestação com Tuta absoluta, com intervalo de 2 dias entre avaliações (values of the areas under the curves of the progress of damage over time to damage the plant (PD); leaflet lesion (LF), percent leaflets attacked (PFA), and estimates of contrasts of interest between tomato genotypes, sampled between 36-54 days after infestation with Tuta absoluta at 2-day interval between assessments). Lavras, UFLA, 2008.

\begin{tabular}{llccc}
\hline \multirow{2}{*}{ Genótipos } & \multicolumn{3}{c}{ Área calculada sob a curva de progresso dos danos ao longo do tempo } \\
\cline { 2 - 4 } & & $\begin{array}{c}\text { Danos nas plantas } \\
\text { (DP) }\end{array}$ & $\begin{array}{c}\text { Lesão nos folíolos } \\
\text { (LF) }\end{array}$ & $\begin{array}{c}\text { \% de folíolos atacados } \\
\text { (PFA) }\end{array}$ \\
\hline T1 & LA-716 & $5,16 \mathrm{f}$ & $5,83 \mathrm{e}$ & $5,16 \mathrm{f}$ \\
T2 & TOM-687 & $22,16 \mathrm{e}$ & $17,50 \mathrm{~d}$ & $18,66 \mathrm{e}$ \\
T3 & TEX-298 & $23,66 \mathrm{ef}$ & $17,66 \mathrm{~d}$ & $18,60 \mathrm{e}$ \\
T4 & TEX-310 & $27,83 \mathrm{cde}$ & $22,66 \mathrm{~cd}$ & $23,33 \mathrm{de}$ \\
T5 & TEX-315 & $32,33 \mathrm{bcde}$ & $25,66 \mathrm{bcd}$ & $28,00 \mathrm{cde}$ \\
T6 & TEX-316 & $31,00 \mathrm{bcde}$ & $26,66 \mathrm{bcd}$ & $26,16 \mathrm{de}$ \\
T7 & TOM-650 & $34,50 \mathrm{abcd}$ & $30,50 \mathrm{abc}$ & $30,16 \mathrm{bcde}$ \\
T8 & TOM-694 & $39,33 \mathrm{abcd}$ & $34,83 \mathrm{abc}$ & $35,66 \mathrm{abcd}$ \\
T9 & TOM-699 & $35,33 \mathrm{abcd}$ & $31,33 \mathrm{abc}$ & $31,33 \mathrm{abcd}$ \\
T10 & TOM-700 & $36,16 \mathrm{abcd}$ & $31,83 \mathrm{abc}$ & $34,16 \mathrm{abcd}$ \\
T11 & Bravo & $43,50 \mathrm{ab}$ & $39,83 \mathrm{ab}$ & $41,83 \mathrm{abc}$ \\
T12 & Bônus & $49,66 \mathrm{a}$ & $46,33 \mathrm{a}$ & $45,66 \mathrm{a}$ \\
T13 Santa Clara & $48,33 \mathrm{a}$ & $43,66 \mathrm{a}$ & $44,33 \mathrm{ab}$ \\
\hline
\end{tabular}

\begin{tabular}{llccc}
\hline \multirow{2}{*}{ Contrastes de interesse } & \multicolumn{3}{c}{ Estimativas dos contrastes } \\
\cline { 2 - 5 } & $\begin{array}{c}\text { Danos nas plantas } \\
\text { (DP) }\end{array}$ & $\begin{array}{c}\text { Lesão nos folíolos } \\
(\text { LF) }\end{array}$ & $\begin{array}{c}\text { \% de folíolos atacados } \\
\text { (PFA) }\end{array}$ \\
\hline C1 & {$[(\mathrm{T} 11+\mathrm{T} 12+\mathrm{T} 13) / 3-\mathrm{T} 1]$} & $42,00 * *$ & $37,44 * *$ & $38,77 * *$ \\
$\mathrm{C} 2$ & {$[(\mathrm{~T} 11+\mathrm{T} 12+\mathrm{T} 13) / 3-\mathrm{T} 2]$} & $25,00 * *$ & $25,77 * *$ & $25,27 * *$ \\
$\mathrm{C} 3$ & $[(\mathrm{~T} 11+\mathrm{T} 12+\mathrm{T} 13) / 3-(\mathrm{T} 3+\mathrm{T} 4+\mathrm{T} 5+\mathrm{T} 6) / 4)]$ & $18,45 * *$ & $20,11 * *$ & $19,90 * *$ \\
$\mathrm{C} 4$ & $[(\mathrm{~T} 3+\mathrm{T} 4+\mathrm{T} 5+\mathrm{T} 6) / 4)-\mathrm{T} 1]$ & $23,54 * *$ & $17,33 * *$ & $18,87 * *$ \\
C5 & $[(\mathrm{T} 3+\mathrm{T} 4+\mathrm{T} 5+\mathrm{T} 6) / 4)-\mathrm{T} 2]$ & $6,54 \mathrm{~ns}$ & $5,66 \mathrm{~ns}$ & $5,37 \mathrm{~ns}$ \\
C6 & $[(\mathrm{T} 7+\mathrm{T} 8+\mathrm{T} 9+\mathrm{T} 10) / 4-(\mathrm{T} 3+\mathrm{T} 4+\mathrm{T} 5+\mathrm{T} 6) / 4)]$ & $7,68 * *$ & $8,96 * *$ & $8,81 * *$ \\
\hline
\end{tabular}

${ }^{1}$ Médias seguidas da mesma letra nas colunas não diferem entre si pelo teste de Tukey ao nível de $5 \%$ de probabilidade ( $\left.\mathrm{p}=0.05\right)\left({ }^{1} \mathrm{means}\right.$ followed by the same letter within the columns do not differ from each other by Tukey multiple range test ( $\mathrm{p}=0.05)$ ); ** significativo a $1 \%$, * significativo a $5 \%$ e ns= não significativo pelo teste de Scheffé $(* *$ significant at $1 \%$, * significant at $5 \%$ and ns=not significant, respectively, for the Scheffé test).

não preferência para oviposição, tanto nos híbridos experimentais (TEX-298, TEX-310, TEX-315 e TEX-316) quanto na linhagem TOM-687 (alto teor de AA) ou no acesso LA-716 (alto teor de AA). Essa associação entre menores oviposições e maiores teores de AA já foram anteriormente relatadas por Maciel (2008) e Gonçalves Neto (2008) que, a exemplo do presente ensaio, também trabalharam com linhagens avançadas com alto teor de AA. A significância do contraste $\mathrm{C} 4$ (híbridos experimentais vs LA-716) (Tabela 2) demonstra todavia que outros fatores presentes no acesso LA-716, além dos AA, podem também desempenhar um papel nos efeitos antagônicos a $T$. absoluta, conclusão corroborada por Maciel (2008).

Os danos medidos nas plantas (DP), as lesões nos folíolos (LF) e as percentagens de folíolos atacados (PFA) foram em geral menores nos híbridos experimentais e na linhagem TOM-687 do que nas linhagens com baixo teor de AA (TOM-650, TOM-694, TOM-699 e TOM-700) ou nas testemunhas comerciais (Bravo, Bônus, Santa Clara) (Tabela 3). Significância (contraste C6, Tabela 3) também foi observada ao comparar os parentais femininos que apresentam baixo teor de AA(TOM-650, TOM-694, TOM-699 e TOM-700) com os híbridos experimentais (TEX-298, TEX-310, TEX-315 e TEX-316), indicando maior resistência dos últimos relativamente às primeiras. Embora não tão resistentes quanto o acesso 'LA-716' (contraste C4, Tabela 3), os híbridos (TEX-298, TEX310, TEX-315 e TEX-316) apresentaram níveis satisfatórios de resistência a T. absoluta. Fica evidente que altos teores (TOM-687) ou intermediários (TEX-298, TEX-310, TEX-315 e TEX316) de AA nos folíolos levaram a uma menor evolução dos danos aos folíolos dos genótipos com baixo teor de AA, sejam eles as testemunhas comerciais (contrastes $\mathrm{C} 2, \mathrm{C} 3$, Tabela 2) ou linhagens parentais (contraste C6, Tabela 3). Não houve diferenças significativas para os níveis de danos entre os híbridos e a linhagem genitora TOM-687 (contraste C5, Tabela 3), indicando que níveis in- 
termediários de AA nos híbridos foram eficientes quanto ao alto nível de AA da linhagem TOM-687 para controlar os danos causados pela traça-do-tomateiro. Embora os dados obtidos indiquem um mecanismo de resistência do tipo não preferência por alimentação, tanto nos híbridos experimentais (TEX-298, TEX-310, TEX-315 e TEX-316) quanto na linhagem TOM-687 (alto teor de AA) ou no acesso LA-716 (alto teor de AA), não se pode excluir a possibilidade de mecanismos de antibiose (o que, no entanto, não foi objeto de estudo nos presentes ensaios). A maior resistência à traça-do-tomateiro de genótipos com maiores teores de AA nos folíolos também foi relatada por Maciel (2008) e Gonçalves Neto (2008), testando outros materiais genéticos. A significância do contraste $\mathrm{C} 4$ (híbridos experimentais vs LA-716) (Tabela 3) demonstra todavia, que outros fatores presentes no acesso LA-716, além dos AA, podem desempenhar um papel nos efeitos antagônicos a T. absoluta.

Todos os resultados obtidos nesta pesquisa reafirmam inferências de outros autores (Resende et al., 2006; Saeidi et al., 2007; Maciel, 2008; Resende et al., 2008) que os AA derivados de $S$. pennellii são o principal fator responsável pelos altos níveis de resistência a pragas e, que a seleção indireta para altos teores de AA é eficiente na obtenção de linhagens melhoradas de tomateiro com bons níveis de resistência. Além de serem o componente mais importante da resistência, os AA têm uma herança simples (Gonçalves et al., 2007), essencialmente monogênica, o que torna particularmente fácil sua introdução em linhagens-elite de tomateiro. Este fato, aliado à recente descoberta de Maciel (2008), confirmada, para a traça-do-tomateiro, no presente estudo, de que híbridos heterozigotos resultantes do cruzamento entre linhagens com altos teores de AA e linhagens com baixos teores de AA apresentaram níveis satisfatórios de resistência a vários artrópodes-praga (traça-do-tomateiro, mosca-branca e ácaro-rajado), trazem novas perspectivas para o melhoramento genético de tomateiro visando à resistência múltipla a pragas. Uma delas é a confirmação obtida nessa pesquisa referente ao potencial agronômico da linhagem rica em AA (TOM-687) quando usado como genitor na obtenção de híbridos de tomateiro com resistência a pragas e doenças, em combinação com linhagens genitoras elite resistentes a múltiplas doenças, obtiveram-se híbridos com potencial competitivo relativamente às cultivares comerciais.

\section{AGRADECIMENTOS}

À FAPEMIG, ao CNPq, à CAPES pelo auxílio financeiro e concessão de bolsas; à UFLA e HortiAgro Sementes Ltda. pela infra-estrutura.

\section{REFERÊNCIAS}

ALVARENGA MAR. 2004. Tomate: produção em campo, casa-de-vegetação e em hidroponia. Universidade Federal de Lavras, 400p.

BENVENGA SR; FERNANDES OA; GRAVENA S. 2007. Tomada de decisão de controle da traça-do-tomateiro através de armadilhas com feromônio sexual. Horticultura Brasileira 25: 164-169.

FERREIRA DF. 2000. Análises estatísticas por meio do Sisvar para Windows 4.0. In: REUNIÃO ANUAL DA REGIÃO BRASILEIRA DA SOCIEDADE INTERNACIONAL DE BIOMETRIA, 45. Anais... São Carlos: Universidade Federal de São Carlos. p.255-258.

GONÇALVES NETO AC. 2008. Seleção para teor de acilaçúcar nas folhas em tomateiro com qualidade comercial confere resistência à traça (Tuta absoluta). Lavras: UFLA. 25p (Tese mestrado).

GONÇALVES LD; MALUF WR; CARDOSO MG; GOMES LAA; NASCIMENTO IR. 2007. Herança de acilaçúcares em genótipos de tomateiro provenientes de cruzamento interespecífico. Pesquisa Agropecuária Brasileira 42: 699-705.

LABORY CRG; SANTA-CECILIA LVC; MALUF WR; CARDOSO MG; BEARZOTTI E; SOUZA JC. 1999. Seleção indireta para teor de 2-tridecanona em tomateiros segregantes e sua relação com a resistência à traça-dotomateiro. Pesquisa Agropecuária Brasileira 34: 733-740.

LIEDLBE; LAWSON DM; SHAPIRO JA; WHITE KK; COHEN DE; CARSON WG; TRUMBLE JT; MUTSCHLER MA. 1995. Acylsugars of wild tomato Lycopersicon pennellii alters settling and reduces ovposition of Bemisia argentifolii (Homoptera: Aleyrodidae). Journal of Economic Entomology 88: 742-748.

MACIEL GM. 2008. Broad spectrum arthropod resistance mediated by leaf acylsugar contents in tomatoes. Lavras: UFLA. 45p (tese mestrado).

MACIEL GM; MALUF WR; SILVA, VF; GONÇALVES NETO AC; HAYATA L; CARVALHO RC; MORETTO P; LICURSI V; MORETTO DP. 2009. Heterose e capacidade combinatória em linhagens de tomateiro na obtenção de híbridos com teores intermediários de acilaçúcares. In: $49^{\circ}$ CONGRESSO BRASILEIRO DE OLERICULTURA, 27. Anais... Águas de Lindóia.

MALUF WR; BARBOSA LV; COSTA SANTACECÍLIA LV. 1997. 2-tridecanone-mediated mechanisms of resistance to the South american tomato pinworm Scrobipalpuloides absoluta (Meyrick, 1917) (LepidopteraGelechiidae) in Lycopersicon spp. Euphytica 93: 189-194.

PEREIRA GVN; MALUF WR; GONÇALVES LD; NASCIMENTO IR; GOMES LAA; LICURSI V. 2008. Seleção para alto teor de acilaçúcares em genótipos de tomateiro e sua relação com a resistência ao ácaro vermelho (Tetranychus evansi) e à traça (Tuta absoluta). Ciência e Agrotecnologia 32: 996-1004.

RESENDE JTV; MALUF WR; FARIA MV; PFANN AZ; NASCIMENTO IR. 2006. Acylsugars in tomato leaflets confer resistance to the South American tomato pinworm, Tuta absoluta Meyr. Scientia Agrícola 63: 20-25.

RESENDE JTV; MALUF WR; CARDOSO MG; FARIA MV; GONÇALVES LD; NASCIMENTO IR. 2008. Resistance of tomato genotypes with high levels of acylsugars to Tetranychus evansi Baker \& Pritchard. Scientia Agrícola 65: 31-35.

SAEIDI Z; MALLIK B; KULKARNI RS. 2007. Inheritance of glandular trichomes and two-spotted spider mite resistance in cross Lycopersicon esculentum 'Nandi' and $L$. pennellii 'LA2963'. Euphytica 231-238.

SUINAGA FA; CASALI VWD; SILVA DJH; PICANÇO MC. 2003. Dissimilaridade genética de fontes de resistência de Lycopersicon spp. a Tuta absoluta (Meyrick, 1917) (Lepidoptera: Gelechidae). Revista Brasileira de Agrociência 371-376. 